\title{
Wellcome and Zeneca form genetic alliance
}

London. In a novel three-way agreement, the Wellcome Trust and the British company Zeneca - formerly the pharmaceutical and life sciences division of ICI - have, together with the University of Oxford, announced plans for collaboration on research into multifactorial genetic diseases.

The three bodies have signed an agreement covering work on the genetics of rheumatoid and osteoarthritis at the Wellcome Trust Centre for Human Genetics. This was set up last year as part of the university's Nuffield departments of medicine and surgery, and brings together more than a hundred researchers at the university and the Oxford Radcliffe Hospitals Trust.

Under the terms of the agreement with what is widely seen as one of Britain's leading research centres into polygenic diseases, Zeneca will provide financial support for research at the centre, in return for which it will be granted options to exploit any drugs that emerge from the identification of relevant genetics targets.

The initial focus will be on bone disorders. But Graham Boulnois, director of biotechnology for Zeneca Pharmaceuticals, emphasizes that collaboration on further disease areas will be explored as opportunities arise. (Other diseases being studied by researchers at the centre include asthma, malaria and migraine.)

At the same time, officials at both the university and the centre claim that the agreement reached with Zeneca, which sets up a framework for close and continuous interaction between university scientists and those in the company, provides a model for potential collaboration with other pharmaceutical companies.

"We are not medicinal chemists, and are anxious to get ourselves locked in with partners that can help turn our discoveries into both diagnostic and therapeutic products," says John Bell, Nuffield professor of medicine at the university and one of the co-founders of the centre.

The three-way agreement, although not unique at a time of increasing collaboration between universities, private research foundations and private companies, nevertheless represents relatively new ground for each of the three partners.

For Zeneca, for example, which has long enjoyed close relationships with researchers in British universities, it is the first major external collaboration to be announced in genetics-related research, and follows the creation of a human genome group within the company last year.

Unlike rival UK pharmaceutical companies such as Glaxo Wellcome, Pfizer and SmithKline Beecham, each of which has announced collaborative deals with small genome-related biotechnology companies, Zeneca has until now been relatively slow in building up such strategic alliances in genetics, although it has well-established links to British universities in more traditional areas.

Boulnois stresses, however, that the agreement with the Wellcome centre is just the first step. "Our intention is that it will be one of a number of interactions that are likely to include other academic centres worldwide, and could include other small biotechnology companies as well," he says.

Wellcome officials hope that the deal will help to answer critics who have been arguing that, up to now, the trust has lacked a strong strategy for ensuring that the results of the

\section{IMAGE UNAVAILABLE FOR COPYRIGHT REASONS}

Follow through: Zeneca scientists will help turn genetic discoveries into products.

research it supports - particularly in the field of human genetics - find their way into the health-care system.

Finally, the decision to negotiate a deal directly with Zeneca and Wellcome under which the intellectual property rights will be held by the trust and licensed to the company, with royalty payments being shared with the university - represents something of a departure from what has up to now been the university's preferred route

of negotiating licensing arrangements through the university's own technology transfer company, ISIS Innovation.

University officials, however, say they are well pleased with the outcome of the negotiations. "In the past, medical charities which have funded work have not appeared to welcome licensing arrangements with industry", says June Clarke, director of research services for the university. "This new agreement is the way forward."

The agreement is not without its sceptics. Some, for example, question whether researchers at the Wellcome centre, which remains primarily devoted to fundamental research, will adjust easily to the pressures of a commercial agreement in which payment will be linked to the successful achievement of formal milestones - the standard practice with biotechnology companies.

But Zeneca officials say that they have been impressed by the attitude of Bell and his colleagues. "They are a highly entrepreneurial group," says Boulnois. "We feel that we have a very good arrangement."

Indeed, Boulnois says that, although the initial agreement with the centre is for a limited period - neither the precise time scale, nor the size of the company's financial commitment is being made public - the link with the centre could, depending on the successful achievement of plans already outlined, "go on for a very long time".

Bell has equal confidence in the arrangement with Zeneca, which he claims is "the only [British] pharmaceutical company with a serious human genome programme". $\mathrm{He}$ adds: "The whole deal has been very satisfactory from everyone's point of view".

Bell says that he is now keen to see similar deals negotiated with other companies, several of which - such as Roche and Merck - have already expressing interest in exploring potential links to research teams at the centre.

David Dickson

\section{AAAS to send forensic experts to Haiti}

Washington. Forensic anthropologists and other volunteers from Argentina, Guatemala and the United States will visit the troubled island of Haiti in September to exhume bodies in search of evidence of human rights violations.

The specialist team is being sent by the science and human rights programme of the American Association for the Advancement of Science (AAAS) at the invitation of a commission established by President Jean-Bertrand Aristide to investigate human rights abuses on the island between 1991 and 1994.

The team will be led by Clyde Snow, a leading US forensic scientist who is at present working on the investigation into the Oklahoma bombing. It will spend four weeks on the island recovering bodies from two mass graves, at Fort Dimanche prison and near the capital, Port au Prince, and assessing their cause of death.

Other team members will help the commission - which is due to report by the end of the year - to establish a computer database to help it track connections between up to 20,000 human rights allegations which it expects to receive from the Haitian public.

Dan Salcedo, who is managing the programme at the AAAS, says that experts involved in two earlier programmes in Argentina and Guatemala will join the Haiti mission.

C. $\mathrm{M}$. 